el argentino Roberto Arlt (Saverio el cruel). Los objetivos principales que la autora persigue al centrar su análisis en este corpus son: explicar cómo se perfila la farsa en Hispanoamérica, exponer la manera en que evoluciona en diferentes dramaturgos de América Latina y dar cuenta de cómo a través de ella se puede expresar una nueva sensibilidad. Finalmente, Dahlia Antonio observa que estos tres dramas comparten una visión crítica frente a un sistema que rige a los individuos. Es decir, constituyen un ataque burlesco al orden, a un microcosmos (generalmente político) de tintes kafkianos, con frecuencia dividido entre opresores y oprimidos.

En el texto de Dahlia Antonio Romero se puede apreciar la vigencia de la farsa en nuestros días. Mediante los ejemplos elegidos se revela este género como una expresión cercana a nosotros los latinoamericanos. Su actualidad se debe en buena medida al tono particular que rige la farsa: la risa dionisíaca, desvergonzada, burlesca. Se trata de un humor que ya es característico de estos pueblos de América Latina, pues nacemos, crecemos y fallecemos rodeados de esa risa insolente con la que se responde a las desgracias impuestas por los poderosos. Así pues, la razón principal por la que se debe considerar vigente la farsa reside en que con ella logramos recrear nuestra realidad con los trazos de la caricatura. Por medio de este género podemos acceder a una forma de denuncia de nuestra lamentable situación, o dicho en las palabras de la autora: "en este mundo al revés que es Hispanoamérica la farsa es nuestro género más realista”. LPyH

Ajelet Cabrera Ruiz es estudiante de Lengua y Literatura Hispánicas en la Facultad de Letras Españolas, uv.

\section{Creatividad y difusión para el son huasteco}

Cancionero tradicional

\section{Obeth Colorado Morales}

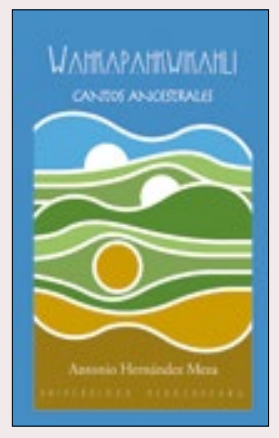

\section{Antonio Hernández Meza,}

Wahkapahkwikahli/Cantos ancestrales. Comp., pról. y notas de Román Güemes Jiménez, Xalapa, uv, 2017, 107 pp.

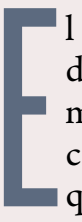
1 son mexicano, estudiado desde diferentes áreas académicas y en los últimos años con un buen nivel de difusión que atiende necesidades de rescate y revaloración de la música tradicional (como es el caso del son veracruzano), ha sido enfocado en su mayoría desde las perspectivas antropológica-histórica y, en algunos casos, etnomusicológica. Con respecto a su difusión, se han realizado diversas estrategias para el rescate, la conservación y, paradójicamente, para la evolución del son tradicional con el aporte de nuevas ideas o propuestas a la tradición.

Las diversas contribuciones al son veracruzano se ven reflejadas tanto en la conservación de elementos tradicionales musicales y extramusicales (por ejemplo, ritualidad y lírica) como en la inclusión de elementos nuevos dentro de un "ámbito de cultura autónoma”, en palabras de Guillermo Bonfil Batalla (1988: 15). Precisamente, lo que se transmite en Wahkapahkwikahli/Cantos ancestrales es "la creatividad expresada en los procesos de innovación que no se da en el vacío, sino en el contexto de una cultura propia y autónoma" (1988).

Es esta la nueva aportación creativa que Antonio Hernández Meza hace a la cultura huasteca, específicamente integrando poesía en lengua náhuatl al son huasteco con la creación de nuevas estrofas y sones. La publicación consta de 27 cantos huastecos, 14 en lengua náhuatl septentrional huasteco, con su traducción al español, y 13 sones en español con su traducción al náhuatl; todos son parte de la obra poética bilingüe de un maestro reconocido como músico tradicional por parte del Consejo Nacional para la Cultura y las Artes.

La difusión que se le ha dado al son huasteco en los últimos años se ve reflejada de diversas maneras, tanto en la investigación como en forma de apoyo, rescate y revaloración; por ejemplo, la gestión de encuentros y concursos del huapango entre tríos huastecos en algunos lugares de esta región, en donde podemos apreciar diversidad de estilos de su son; con la creación de nuevos tríos y la conservación de aquellos tradicionales de reconocida trayectoria, como es el caso del Tlayoltiyane.

Por medio de los tríos huapangueros el maestro Antonio Hernández Meza fue forjando una fecunda trayectoria desde sus inicios y ahora pone en juego su creatividad como portador de una tradición cultural con características regionales de diferentes estilos en la interpretación del huapango y el son huasteco, lo cual podemos apreciar en su gran proyecto 


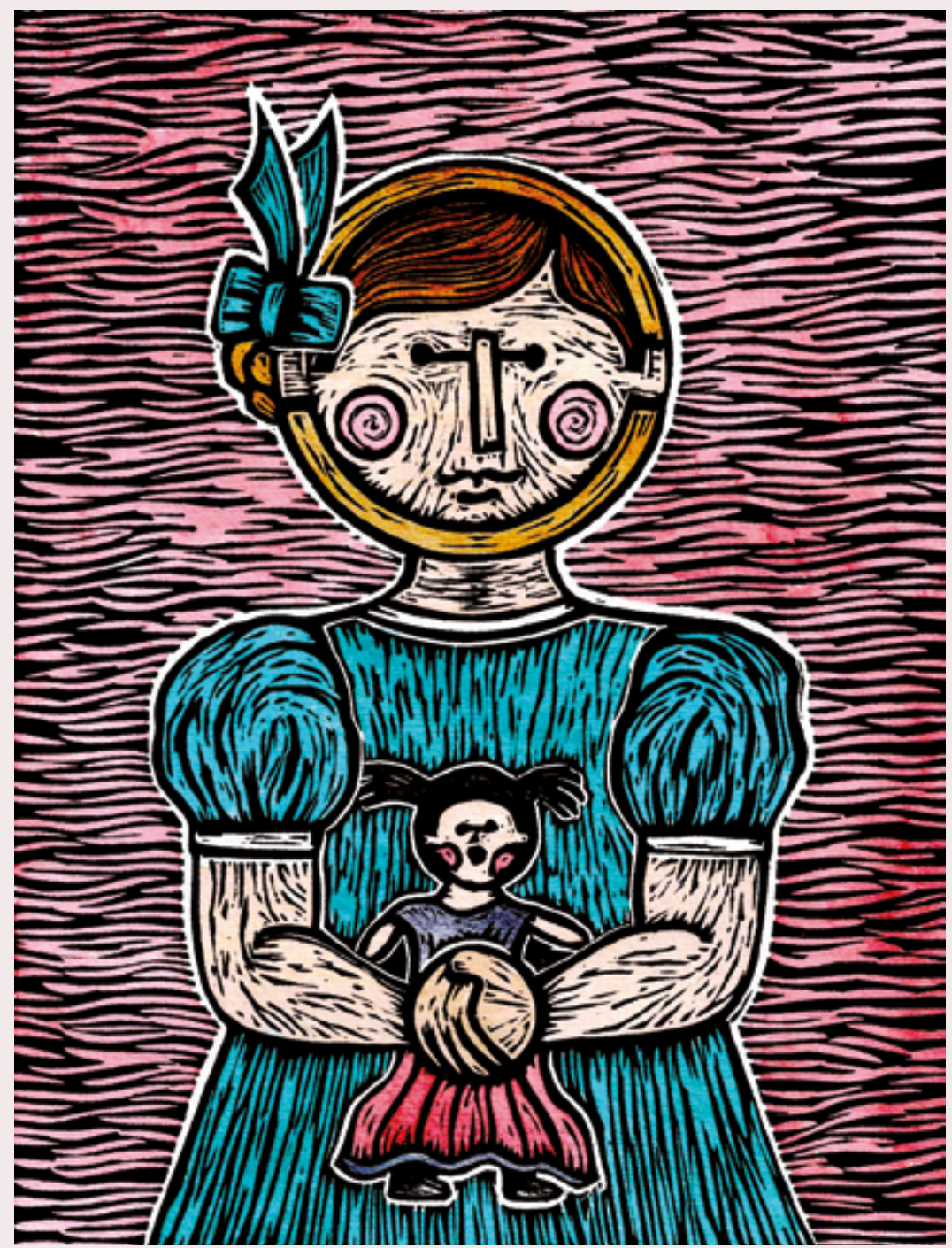

Niña con muñeca nes de costumbre de raigambre indígena; por ejemplo, como señala Román Güemes en una de sus notas, "Xochitpitsawak es una cadena de sones (xochipitsawaksones) dentro del mundo sonoro de los sones de costumbre" y alude a la versión que interpreta el Trío Tlayoltiyane, la cual "se toca en tono de sol por ser la más difundida fuera del contexto ritual" en comparación con la versión en re, "versión original" con "un carácter eminentemente ritual".

También el antropólogo, en esta compilación, hace mención de otra serie de sones de costumbre muy interesantes, como los elosones (sones para los elotes) o xochisones (sones de flor o costumbre), así como los llamados xochipitsawak canarios y los sones de orfandad, iknosones. Esta información permite hacia los investigadores o aficionados amantes del son huasteco, otro acercamiento a su amplia tradición musical-poética.

En relación con la lírica de estos cantos compilados, Antonio Hernández Meza demuestra su destreza y talento en la poesía tanto en su lengua materna, el náhuatl, como en español. Román Güemes señala en el son "Yehyektsih Elwikatl" (Cielito Lindo): "la forma como debe escribirse la seguidilla: su estructura tiene que obedecer a la forma clásica de combinar versos heptasílabos y pentasílabos”. Dicha forma la realiza con maestría el "poeta indígena", designación que muy acertadamente ha dado Román Güemes a Antonio Hernández, quien, "por su voz y falsete, ha sido reconocido en la Huasteca como uno de los cantores vivos más importantes del son”.

Indudablemente la publicación de Wahkapahkwikahli/Cantos ancestrales es el reflejo de toda una tradición musical heredada a Antonio Hernández, así como el resul-
De las experiencias y trabajo constante con el Trío Tlayoltiyane, se publica en forma de cancione- ro Cantos ancestrales, respaldado con notas y prólogo del antropo logo Román Güemes Jiméne quien también habla náhuatl y fue responsable de la compilación los cantos que conforman el lla información específica, ya sea de algún son, de alguna característica poética o las tradiciones en torno al son huasteco.

En la tradición musical huasteca existe un gran número de títulos que conforman el repertorio del huapango, o sones huastecos que pertenecen a los llamados so- 
tado del trabajo realizado con sus dos hijos en el Trío Tlayoltiyane. Estos sones combinan lo que pudo ser parte del canto prehispánico con una influencia afro-hispana, como bien señalaba Manuel Álvarez Boada sobre los huapangos tradicionales: "derivan de antiguas formas o géneros de la música popular española"; añade el mismo autor que "la fusión de formas musicales europeas con lo indígena y africano dio lugar a una expresión con carácter propio y regional, que en constante transformación iría diferenciándose en cada uno de los lugares e intérpretes" (1985).

Por lo tanto, el principal aporte de esta publicación es la difusión y conservación de sones huastecos tradicionales, pero al mismo tiempo la inclusión de nuevos sones al repertoriohuasteco, procedentes tanto del canto mestizo como prehispánico ancestral derivado de una lengua materna náhuatl, que aún sigue viva en la tradición musical del compositor, poeta y músico Antonio Hernández Meza. LPyH

\section{REFERENCIAS}

Álvarez Boada, Manuel. 1985. La música popular en la Huasteca veracruzana. México: Premià.

Bonfil Batalla, Guillermo. 1988. "La teoría del control cultural en el estudio de procesos étnicos". Anuario Antropológico/86, 13-53. Brasilia: Universidad de Brasilia/Tempo Brasileiro.

Hernández Azuara, César. 2003. El son huasteco $y$ sus instrumentos en los siglos XIX y XX. México: ciesas. Programa de Desarrollo Cultural de la Huasteca.

Obeth Colorado Morales es maestro en Música con especialidad en Teoría de la Música por la uv.

\section{EI poeta y el numen}

Poesía

\section{Maximiliano Sauza Durán}

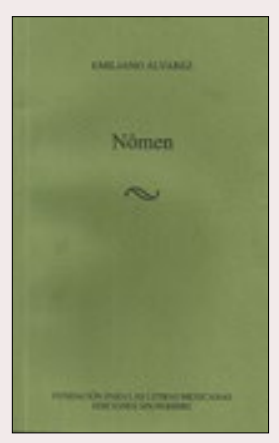

\section{Emiliano Álvarez,}

Nômen. Un ensayo. México, FLM/Ediciones Sin Nombre, 2017, 68 pp.

E 1 poeta es quien nombra las cosas por vez primera. Nombrar, empero, es algo que también suelen hacer los dioses. "En el Principio era el Verbo", pregona la Biblia. Pachacamue, deidad funesta de los machiguengas peruanos, fue decapitado y su cabeza se destinó al enterramiento en la anónima selva, pues todo lo que su lengua proclamaba devenía catástrofe. (Olvidaron sus destructores, sin embargo, arrancarle la lengua de la boca, una vez exiliada en el anónimo entierro.) Homshuk, el niño que nació de un huevo según la mitología popoluca, ofendido por los entes del Mundo, se vengó nombrándolos, marcando sus destinos al viento, al río, al monte, a la selva.

En efecto, Nômen recuerda a numen. Este poemario de manufactura artesanal de Emilio Álvarez (autor, entre otros divertimentos, de los libros objeto Papa- lote [2013], El escenario [2015] y Salvia [2016]) se dedica a la creación de deidades íntimas. Siete partes dividen su estructura: Prólogo, cinco secuencias enumeradas y Epílogo.

"Un viejo vagabundo recorre las ruinosas piedras de un anfiteatro", se advierte en el Prólogo. ¿Y quién es ese viejo vagabundo? ¿El yo poético que instaura el autor, nacido apenas en 1987? ¿Es acaso un numen, un asceta, una visión, un sueño? Sea quien sea, "El viejo dice 'vaca', y una mancha de aire manchado muge / y se come la hierba”.

Ese viejo trickster, ese poeta que señala, nombra y condena, advierte después la aparición del verdadero numen: una mujer (¿musa, sueño, visión, alter ego?): "Estabas tú completa, / y yo solo conservo estos pedazos". Pedazos descritos a lo largo de las cinco secuencias de imágenes y fragmentos dispersos, inscritos en la memoria, en la experiencia abstraída. El poeta y el numen se confunden en la multitud de sílabas.

El numen es nombrado pero su nombre nunca se conoce. Nadie tiene parentela ni apellidos. ¿Es acaso el viejo vagabundo, Quetzalcóatl, deidad que nombra y habita el aire de las palabras? ¿Es la mujer-deidad, acaso, Chalchiuhtlicue, de cuyas piernas "salen / corrientes $[\ldots]$ que son miles de ríos puros"?

Poema y cosa se vuelven uno mismo. Devienen irreconocibles, inseparables. Uno remite al otro. A lo largo del recorrido lírico que nos presenta Emiliano Álvarez, la experiencia que distorsiona los sentidos se vuelve vital en este poemario que palpita a cada palabra. El poeta llama las sílabas $y$ estas se ordenan en constantes y caudalosos momentos:

El olor a cosa llena del

[silencio se vuelve un estanque, en donde el 